\title{
ENTRE HISTÓRIAS: A LEITURA \\ DAS DÉCADAS DE JOÃO DE BARROS \\ NA METRÓPOLE E NA AMÉRICA \\ PORTUGUESA
}

Ricardo Souza de Carvalho Universidade de São Paulo

\section{Primeiras histórias}

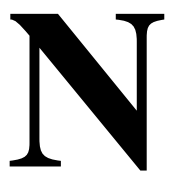

o século XVI, apogeu da expansão ultra-marina, o português João de Barros (1496-1570) planeja uma obra de fôlego, uma espécie enciclopédia histórico-geográfica, as Décadas, formada por três partes: Milícia, Navegação e Comércio. A Milícia relataria as conquistas portuguesas na Europa, na Ásia, na África e em Santa Cruz (o Brasil). No entanto, foram publicados apenas quatro volumes que correspondiam às Décadas da ÁsiaDos feitos que os Portugueses fizeram no descobrimento e conquista dos mares e terras do Oriente: o primeiro volume, ou Primeira Década, é de 1552, o segundo é de 1553, o terceiro é de 1563, e o quarto, póstumo, é de 1615. Denominam-se Décadas porque cada volume é formado por dez livros, ou seja, dez partes.

João de Barros, aos 24 anos, escrevera uma novela de cavalaria, a Crônica do Imperador Clarimundo donde os Reis de Portugal descendem (1520). Segundo o próprio Barros, no prólogo à Primeira Década da Ásia, sua novela de cavalaria foi "uma pintura metafórica de exércitos e vitórias humanas, nesta figura racional do imperador Clarimundo, título da traça (conforme a idade que eu então tinha) afim de aparar o estilo de minha possibilidade pera esta vossa Ásia". ${ }^{1}$ A

${ }^{1}$ BARROS, 1988. p.3. 
novela de cavalaria, além de "aparar" o estilo para sua obra posterior, apresentava, em meio a terras e personagens exóticos, um antepassado dos reis portugueses, o imperador Clarimundo. Através do episódio do gigante que faz profecias a Clarimundo sobre os reis de Portugal, o jovem escritor ensaia os primeiros passos rumo à "História" e à glorificação da pátria.

Obras, aparentemente distintas, têm as fronteiras pouco nítidas: a ficção desgarrada da novela de cavalaria apresenta elementos históricos, enquanto a obra histórica que aspira à verdade narra os acontecimentos como se eles fossem ficção. No Livro Quarto da Primeira Década, que versa sobre a viagem portuguesa à India, Vasco da Gama se assemelha a um cavaleiro andante, ou melhor, "cavaleiro navegador", combatendo os mouros hereges, dragões presentes em todos os lugares.

João de Barros queria oferecer a Portugal uma grande obra que exprimisse o orgulho nacional, pois os portugueses seriam avessos às letras e prefiririam as ações. Porém, em 1572 a epopéia Os Lusíadas de Luís de Camões concentrou em dez cantos as diversas Décadas pretendidas por João de Barros. Os doze capítulos do Livro Quarto da Primeira Década da Ásia, que narram a viagem de Vasco da Gama à India, constituem provavelmente uma das referências para a composição de Os Lusíadas.

A seqüência narrativa é linear na obra de Barros: inicia-se com a decisão do rei em mandar uma esquadra a India e termina com a fundação da ermida de Belém. Embora Vasco da Gama seja o protagonista nos demais capítulos, o rei Dom Manuel estabelece a moldura da história. Os títulos dos capítulos inicial e final são os únicos em que o rei é sujeito das ações:

Capítulo primeiro. Como el rey dom Manuel no segundo ano seu reinado, mandou Vasco da Gama com quatro velas ao descobrimento da India.

Capítulo décimo-segundo. Como el rey dom Manuel em louvor de Nossa Senhora fundou na sua ermida de Belém que estava em Restelo um suntuoso templo que depois tomou por jazigo de sua sepultura. 
Se a ordem e a recompensa do rei organizam o Livro Quarto, Os Lusíadas apresentam o monarca como sendo mais uma das personagens da história portuguesa. Camões não inicia o poema com o rei e sua decisão, mas em pleno mar, in media res. O rei só aparece em primeiro plano na narrativa de Vasco da Gama ao rei de Melinde, flash-back não só da viagem até aquele momento, mas da história de Portugal. D. Manuel, mais do que a autoridade máxima, é o homem que sonha e prevê as conquistas portuguesas. Para o rei de Barros tudo se limita às necessidades econômicas e religiosas da dinastia portuguesa, enquanto para o rei de Camões o sonho se impõe, invenção que se quer fazer História. O sonho, além de humanizar esse monarca, afasta a epopéia da historiografia oficial, a qual registra apenas os solenes pronunciamentos.

A personagem do rei, apesar de sua importância em ambas as narrativas, moldura decisiva nas Décadas, personagem histórica e ficcional em Os Lusíadas, não interfere no destino de Vasco da Gama e sua esquadra. Barros e Camões utilizam-se de recursos diversos para marcar o movimento da narrativa, o encadeamento das ações.

Nas Décadas o processo histórico é traçado a partir da providência divina. Deus, em favor da ação portuguesa pelos mares, é apresentado em vários momentos como a solução dos conflitos ou alteração da má sorte: "Mas como as que Deus ordena, não se podem contrariar pelos homens, ainda que em alguma maneira pareça que as impedem (...)”2 A História está nas mãos de Deus. Por outro lado, quando algo desfavorável acontece aos portugueses, o demônio surge: "Finalmente com esta história, ora fosse fingida pera os induzir os outros (posto que sem eles estavam bem movidos contra os nossos) ora que o demônio lhe quis representar aquele seu futuro mal (...)"3

Em Os Lusíadas temos os deuses, reunidos no Olimpo sob o cetro de Zeus, discutindo e decidindo o destino dos portugueses. Se em Barros a contraposição dá-se entre Deus e o Demônio - os

2 BARROS, 1988. p.153.

${ }^{3}$ BARROS, 1988. p.152. 
quais nunca chegam à categoria de personagens, sendo apenas entidades -, em Camões dá-se entre Vênus e Baco, este inclusive infiltrando-se entre os homens para melhor executar as intrigas contra os portugueses.

Ambas as obras narram o conflito entre os portugueses e os mouros. Estes, comerciantes importantes em Calecut, serão um dos principais obstáculos para a última etapa da aventura portuguesa.

João de Barros, deixando o ficcionista falar mais alto, demarca os momentos de tensão e suspense nos três capítulos dedicados aos setenta e quatro dias de permanência portuguesa na India. O historiador oferece uma explicação de ordem econômica à consulta dos mouros sobre a vinda de Vasco da Gama: por serem "senhores" no comércio das especiarias, sentiam ameaçada sua hegemonia na região. No mesmo encontro, são consultadas algumas pessoas "que viam do ofício de astrologia e doutras artes que daqui dependem", e uma delas vê num vaso de água a chegada de velas de muito longe, que queriam destruir a India. Além disso, não podiam se esquecer que se tratavam de "gente cristã", "capital inimiga de mouros". A seguir, João de Barros coloca em dúvida a veracidade da previsão, admitindo que podia ser "fingida" para induzir os outros, ou que fosse uma representação do demônio. Finalmente, subornam o Catual, que seria o intermediário na intriga contra os portugueses frente ao rei. Mais uma vez, a astúcia e a perfídia caracterizam as personagens dos mouros.

Se os títulos dos capítulos, baseados nas novelas de cavalaria, que sumarizavam os principais lances da narrativa, são decisivos na obra de Barros para manter o suspense, em Camões ganham importância as conjunções adversativas, indício de alteração da ordem. Na estrofe 45 do canto oitavo, na qual se apresentam os adivinhos que prevêem maus acontecimentos ligados à vinda portuguesa, temos a conjunção entretanto:

Entretanto, os arúspices, famosos

$\mathrm{Na}$ falsa opinião que em sacrifícios

Antevêem sempre os casos duvidosos 
Por sinais diabólicos e indícios, Mandados do Rei próprio, estudiosos,

Exercitavam a arte e seus ofícios

Sobre esta vinda desta gente estranha,

Que às suas terras vem da ignota Espanha.

Em Os Lusíadas os mouros entram em cena quando Baco, em forma de profeta, aparece em sonho para um deles (estrofes 47-51) e alerta-o da ameaça representada pelos portugueses.

$\mathrm{Na}$ instauração do conflito, Barros oscila entre a História e a ficção: começa com uma justificativa sobre o comércio das especiarias, juízo de um historiador pertinente, mas se volta para os casos duvidosos, não comprovados, como o dos videntes, que revelam de um lado o caráter profano dos mouros, e de outro, um episódio digno de uma novela de cavalaria. Camões, por sua vez, envolvese diretamente na ficção, dispensando, nesse ponto, qualquer fundamentação histórica. A personagem mitológica Baco aparece, então, para mesclar os planos dos deuses e dos homens.

\section{Descobrimentos do Brasil}

João de Barros e Camões tornaram-se referência importante do mundo intelectual lusitano, inclusive para um reduzidíssimo número dos filhos da América portuguesa. Frei Vicente do Salvador, na dedicatória ao licenciado Manuel Severim, na sua História do Brasil, louva três historiadores: João de Barros, Luís de Camões e Diogo Couto. ${ }^{4}$ O Camões de Os Lusíadas é antes visto como historiador, do que como poeta.

Uma das grandes autoridades em história portuguesa, nesse período, é João de Barros. Na América portuguesa, deixa seguidores, dos quais o primeiro é Pero de Magalhães Gandavo, que publica em 1576, História da província de Santa Cruz a que vulgarmente

${ }^{4}$ SALVADOR, 1982. 
chamamos Brasil. No século seguinte, destaca-se o já mencionado Frei Vicente do Salvador, cuja História do Brasil, concluída em 1627, permaneceu inédita até o século XIX, quando foi publicada pelo historiador Capistrano de Abreu.

O século XVIII é marcado pelo surgimento de várias academias, sob inspiração da Metrópole, que congregam os poucos homens de letras da América portuguesa. De acordo com Antonio Candido, sinalizam a passagem das manifestações literárias para a configuração do sistema literário. ${ }^{5}$ No esboço de um primeiro sentimento nativista, a historiografia ganha relevo dentre as atividades da Academia.

Data de 1724 a primeira delas, a Academia Brasílica dos Esquecidos, na Bahia, e de seis anos depois seu fruto mais expressivo, a História da América Portuguesa desde o ano de 1500 do seu descobrimento até ao de 1724, de Sebastião da Rocha Pita (1661-1738). Ainda com Antonio Candido, a obra "de certo modo coroa a primeira era da nossa literatura", ${ }^{6}$ tornando-se não só referência histórica, mas sobretudo literária na América portuguesa.

Como seu mestre João de Barros, Rocha Pita parece ter escrito uma novela imitando o Palmerim de Inglaterra, do português Francisco de Morais. No entanto, prefere dedicar-se a gêneros mais nobres, partindo para a historiografia. Movido por João de Barros e pelo sopro épico de Camões, Rocha Pita escreve uma obra entre os "preceitos da História" e a "frase Poética". Não só as autoridades já o notavam, para uma das quais "lhe parece mais elogio, ou panegírico, que História", como também o próprio autor nas Advertências:

(...) Que como nos dois primeiros livros descreve o corpo natural, e material desta Região, as maravilhosas obras, que nela fez a natureza, as admiráveis produções em vários gêneros, e espécies, e as suntuosas fábricas, que para o trato civil, e Político das suas Povoações foi compondo a arte, no retrato de tanta formosura,

\footnotetext{
${ }^{5}$ CANDIDO, 1997.

${ }^{6}$ CANDIDO, 1997. p.24.
} 
presada a ser pincel a pena, não teme sair dos preceitos da História, quando altera a pureza das suas leis com as idéias da pintura, que requer mais valentes fantasias, tendo por exemplar portentos, em que a mais elevada frase Poética é verdade ainda mal encarecida.

Que nos outros livros, que contêm matérias Políticas, leva o estilo Histórico com estudo castigado, e não põe nas margens, os numerosos rios, e as várias espécies das produções do Brasil, porque sendo tanto do institudo desta obra, entende, que devem ir no corpo dela. $^{7}$

O papel das Décadas em relação a Os Lusíadas em Portugal, será desempenhado pela História de Rocha Pita em relação às tentativas épicas na América portuguesa. Os candidatos a poetas épicos não buscam apenas assuntos na autorizada História de nossa primeira Academia; chegam a transcrever quase que ipse literis passagens mais propícias à poesia do que à prosa. É o caso de Santa Rita Durão em seu Caramuru (1781), no qual Antonio Candido observa que a descrição do Brasil feita por Diogo ao rei da França no canto VII:

(...) é uma pura e simples transposição em verso dos trechos correspondentes de Rocha Pita. Neste, a celebração da flora tropical, feita com bela e colorida prosa barroca, obedece tonalidade tão acentuadamente poética que Durão pôde copiar, não apenas a ordem da descrição, mas os conceitos, as imagens, as próprias palavras. ${ }^{8}$

Dessa rede de autores e obras, podemos estabelecer várias relações. Entre elas, destacamos nesse ensaio o episódio do descobrimento do Brasil. Apesar de sua fonte ser a Carta de Pero Vaz de Caminha, esta permaneceu inédita até o século XIX, quando foi divulgada por Aires Casal, em Corografia Brasílica (1817). Dessa maneira, durante quase três séculos, uma das referências para esse episódio foi o segundo capítulo do Livro Quinto da Primeira década da Ásia de João de Barros. A análise comparativa deste capítulo com

7 PITA, 1730.

${ }^{8}$ CANDIDO, 1993. p.172. 
a versão de Rocha Pita oferece-nos um exemplo das tentativas de construção da narrativa fundadora de uma nação.

O episódio do descobrimento do Brasil esteve presente em vários ensaios de uma grande narrativa nacional. Ainda na América portuguesa, o padre Domingos da Silva Teles, da Academia Brasílica dos Renascidos, idealizou uma Brasileida ou Petreida. ${ }^{9}$ Em 1840 , Varnhagem publica a ficção Crônica do descobrimento do Brasil.

No Livro Quinto da Primeira Década da Ásia, Barros narra a segunda expedição portuguesa à India, comandada por Pedro Álvares Cabral. O capítulo II intitula-se "Como partido Pedro Álvares teve um temporal na paragem do cabo Verde: e seguindo sua derrota descobriu grande terra a que comumente chamamos Brasil, a qual ele pôs nome Santa Cruz. E como antes de chegar a Moçambique passou um temporal que perdeu quatro velas". O descobrimento do Brasil, na obra de Barros, seria um episódio localizado entre duas tempestades, a primeira das quais seria sua causa direta. Episódio que, no interior da grande narrativa proposta pelas Décadas, faz parte da história portuguesa. Por outro lado, Barros afirma que na parte de sua obra dedicada à Santa Cruz "o princípio dela começa neste descobrimento: lá fazemos mais particular menção desta chegada de Pedro Álvares e assim do sítio e coisas da terra." 10 Provavelmente nessa parte da Conquista, a narrativa do descobrimento do Brasil teria o valor inaugural para uma primeira narrativa sobre a América portuguesa. No entanto, no capítulo sob análise, predomina a perspectiva do português João de Barros, na qual esse descobrimento representava apenas mais uma terra que se anexaria à Coroa de Portugal.

A narrativa do descobrimento nas Décadas possui dois momentos básicos: o primeiro encontro entre os portugueses e os índios, e a realização da primeira missa. No primeiro contato, apresenta-se a impressão dos portugueses em relação aos índios, os

${ }^{9}$ CANDIDO, 1993. p.77.

${ }^{10}$ BARROS, 1988. p.174. 
quais eram muito diferentes dos povos já vistos. Quando os portugueses se aproximam, Barros atruibui aos indios um grande medo: “(...) como viram que a frota se vinha contra eles, e que o batel tornava outra vez a praia, fugiram dela: e puseram-se em um teso soberbo, todos apinhoados a ver o que os nossos faziam". ${ }^{11}$

As tentativas de "entendimento", seja através de algumas línguas, seja através de gestos, foram inúteis. No entanto, no dia seguinte, os índios pareceram menos esquivos, e assim foi possível realizar-se a primeira missa. João de Barros admira-se com a inesperada reação dos índios frente à cerimônia:

(...) todos se punham em joelhos usando dos autos que viam fazer aos nossos, como se tiveram notícia da divindade a que se humildavam. $\mathrm{E}$ ao sermão estiveram mui prontos mostrando terem contentamento na paciência e quietação que tinham, por seguir o que viam fazer os nossos: que foi causa de maior contemplação e devoção vendo quão oferecido estava aquele povo pagão a receber doutrina de sua salvação, se ali houvera pessoa que os podera entender. ${ }^{12}$

Do suspense dos índios "apinhoados no teso" partimos para os índios ajoelhados frente a uma cruz. De um dia para o outro, a narrativa do descobrimento vai do desencontro entre dois povos ao encontro repentino do sentimento religioso.

O que correspondia a mais ou menos três páginas nas Décadas reduz-se apenas aos parágrafos cinco e seis do Livro Primeiro na História de Rocha Pita, denominados Descobrimento do Brasile Nomes que lhe foram impostos. Vários elementos foram sintetizados ou eliminados na versão de Rocha Pita para o descobrimento do Brasil.

Se em Barros a narrativa do descobrimento é apenas um episódio da expansão ultra-marina portuguesa, em Rocha Pita é o episódio das origens, do nascimento de uma grande narrativa que se quer construir. Basta comparar a marcação temporal dada por ambos para o descobrimento. Em Barros, é simples e objetiva,

${ }^{11}$ BARROS, 1988. p.173.

${ }^{12}$ BARROS, 1988. p.174. 
seguindo os passos dos velhos cronistas: "E havendo já um mês que ia naquela grande volta, quando veio a segunda oitava da páscoa que eram vinte e quatro de abril, foi dar em outra costa de terra firme (...)" ${ }^{13}$ Rocha Pita transforma um fato e sua simples marcação temporal numa ocorrência singular em meio a marcações temporais baseadas em acontecimentos naturais, religiosos e históricos:

Tinha já dado o sol cinco mil e quinhentas e cinqüenta e duas voltas ao zodíaco, pela mais apurada cronologia dos anos, quando no de mil e quinhentos da nossa redenção (oito depois que a Cristovão Colombo levou a especulação a demandar as Índias) trouxe a tempestade a Pedro Álvares Cabral a descobrir o Brasil. ${ }^{14}$

Os adjetivos são fartos, realçando e valorizando os elementos principais da narrativa: Pedro Álvares Cabral é "ilustree famoso capitão", governando "uma formosa armada de treze poderosas naus".

Em Barros o descobrimento é conseqüência do temporal sofrido junto às ilhas de Cabo Verde. Em Rocha Pita, no entanto, sua causa é devido à "altíssima Providência mais que dos porfiados ventos".

Se nesses dois parágrafos Rocha Pita suprime o primeiro contato entre portugueses e índios, segue, porém, as indicações de Barros em relação à conversão religiosa dos índios na primeira missa. A religiosidade, na História da América Portuguesa, não está apenas nos "bárbaros" índios, como também na "inculta" natureza, que se transfigura para melhor retratar a cerimônia:

(...) sobre uma ara que levantou entre aquele inculto arvoredo, que lhe serviu de dossel e de templo, a cujas católicas cerimônias estiveram admirados, mas reverentes, todos aqueles bárbaros, e conformes com o exemplo dos fiéis, premissas do afeto com que depois abraçaram a nossa religião. ${ }^{15}$

\footnotetext{
13 BARROS, 1988. p.173.

${ }^{14}$ PITA, 1976. p.20.

15 PITA, 1976. p.20.
} 
João de Barros com suas Décadas oferece a matéria histórica para obras que afirmam a literatura portuguesa, no caso de Os Lusíadas, e para obras que participam do processo de formação da literatura brasileira, no caso da História da América Portuguesa.

\section{Referências Bibliográficas}

BARROS, João de. Primeira Década da Ásia. Edição fac-símile. Lisboa: Imprensa Nacional-Casa da Moeda, 1988.

CAMÕES, Luís de. Os Lusíadas. Introdução e notas Alexei Bueno. Rio de Janeiro: Nova Fronteira, 1993.

CANDIDO, Antonio. Formação da literatura brasileira (Momentos decisivos). $1^{\circ}$ vol. (1750-1836). 7.ed. Belo Horizonte; Rio de Janeiro: Editora Itatiaia, 1993.

CANDIDO, Antonio. Iniciação à literatura brasileira (Resumo para principiantes). São Paulo: Humanitas Publicações - FFLCH/USP, 1997.

PITA, Sebastião da Rocha. História da América Portuguesa. Lisboa: 1730.

PITA, Sebastião da Rocha. História da América Portuguesa. Belo Horizonte: Ed. Itatiaia; São Paulo: EDUSP, 1976.

SALVADOR, Frei Vicente do. História do Brasil (1500-1627). 7.ed. Belo Horizonte: Itatiaia; São Paulo: Edusp, 1982.

SARAIVA, Antonio José e LOPES, Óscar. História da literatura portuguesa. 9.ed. Porto: Porto Editora, 1976. 


\section{Resumo}

O ensaio analisa a repercussão das Décadas do historiador português João de Barros em Os Lusiadas de Luís de Camões e na História da América Portuguesa de Sebastião da Rocha Pita. Comparamos o episódio da viagem de Vasco da Gama a India na obra de João de Barros e em Os Lusíadas, e o descobrimento do Brasil nas Décadas e na História de Rocha Pita. As obras em questão, na fronteira entre História e ficção, participam do processo de afirmação e/ou criação de uma literatura.

\section{Resumén}

El ensayo analiza la repercusión de las Décadas del historiador portugués João de Barros en Os Lusíadas de Luis de Camões y en História da América Portuguesa de Sebastião da Rocha Pita. Comparamos el episodio del viaje de Vasco da Gama a India en la obra de João de Barros y en Os Lusíadas, y el descubrimiento de Brasil en Décadas y en la História de Rocha Pita. Las obras en cuestión, en la frontera entre Historia y ficción, participan del proceso de afirmación y/o creación de una literatura. 